\title{
American tegumentary leishmaniasis: correlations among immunological, histopathological and clinical parameters
}

\author{
Ana Luiza Grizzo Peres Martins ${ }^{1}$ \\ José Roberto Pereira Lauris ${ }^{3}$
}

\author{
Jaison Antonio Barreto ${ }^{2}$ \\ Ana Claudia Grizzo Peres Martins ${ }^{4}$
}

\begin{abstract}
BACKGROUND: American tegumentary leishmaniasis has an annual incidence of 1 to 1.5 million cases. In some cases, the patient's immune response can eliminate the parasite, and the lesion spontaneously resolves. However, when this does not occur, patients develop the disseminated form of the disease. OBjectivE: To investigate the association between clinical, laboratory and pathological findings in cases of American tegumentary leishmaniasis. METHODS: A retrospective study of the medical records of 47 patients with American cutaneous leishmaniasis. Clinical, laboratory and epidemiological data were collected, and semi-quantitative histopathological analyses were performed using the Spearman correlation coefficient $(p<0.05)$. RESULTS: Mean patient age was 40.5 years. A total of $29.7 \%$ individuals were female and $70.2 \%$ were male, and $40.4 \%$ of the patients were farmers. The ulcerative form was found in $53.2 \%$ of patients, of whom $59.6 \%$ had lesions in the limbs. The average time to diagnosis was 22.3 months. The following positive correlations were significant: age and duration of the disease, Montenegro reaction, degree of granulomatous transformation and epithelioid cell count; duration of disease, Montenegro reaction and number of lymphocytes; epithelial hyperplasia and edema, hemorrhaging, and epithelial aggression; number of plasmocytes and number of parasites. The main negative correlations found were as follows: age and serology; time and parasite load; epithelial hyperplasia and degree of granulomatous transformation. ConCLUSION: The long duration of the disease could be explained by the fact that lesions were relatively asymptomatic, and therefore ignored by patients with low literacy levels. Individuals may have simply waited for spontaneous healing, which proved to be dependent on the activation of hypersensitivity mechanisms.
\end{abstract}

Keywords: Adaptive immunity; Epidemiologic factors; Leishmaniasis, mucocutaneous

\section{INTRODUCTION}

American tegumentary leishmaniasis (ATL) is a parasitic disease caused by protozoans of the genus Leishmania which are transmitted by phlebotomine insects. The promastigote is introduced into the vertebrate host and phagocytized by cells in the mononuclear phagocyte system, where they differentiate into amastigotes, proliferate, and establish an infection. ${ }^{1}$

In the Americas, the disease is mainly caused by Leishmania (Viannia) braziliensis and L. (Leishmania) mexicana. ${ }^{2,3}$

ATL is one of the most common parasitic infections in the world, with an annual incidence of 1 to 1,5 million cases for cutaneous leishmaniasis and of
500,000 cases for the visceral form of the disease. The number of cases of cutaneous leishmaniasis reported in Brazil has grown steadily over recent years. ${ }^{2}$

Throughout most of its history, ATL was considered a professional disease, as most of the affected individuals were adult males exposed to forested areas. However, its epidemiology has changed considerably over the past few decades, as the vector has adapted to peri-domiciliary areas in rural regions, and has infected a growing number of women and children. ${ }^{3}$

The incubation period of the cutaneous form of the disease can range from one to 12 weeks, with mucosal lesions generally appearing one to two years

Approved by the Advisory Board and accepted for publication on 14.02.2013.

* This study was conducted at the Lauro de Souza Lima Institute (ILSL) - São Paulo (SP), Brazil.

Financial support: none.

Conflict of interests: none.

Dermatologist - Residency preceptor, Lauro de Souza Lima Institute (ILSL). Private medical practitioner - São Paulo (SP), Brasil.

Doctor in Dermatology at the São Paulo University (Universidade de São Paulo; USP) - Head of the epidemiology department of the Lauro de Souza Lima Institute (ILSL) - São Paulo (SP), Brazil.

Doctor in Science at the São Paulo University (Universidade de São Paulo; USP) - Associate Professor at the Bauru School of Odontology of the São Paulo University (FOB-USP) - São Paulo (SP), Brazil.

Physician, Santos School of Medical Sciences - Dermatology Resident at the Clinical Hospital of the São Paulo University (HC-USP) - São Paulo (SP), Brazil. 
after the start of the infection. ${ }^{4}$ ATL may manifest in several different ways, ranging from self-limiting cutaneous lesions to disfiguring mucocutaneous ulcerations. These differences in clinical presentation are generally associated with individual variations in immunological response and with different species of infecting parasites. The variations in the clinical manifestations of ATL pose a diagnostic hurdle for physicians, who tend to only make diagnoses when the disease is strongly suspected. ${ }^{5}$

The localized cutaneous form of ATL is characterized by one or more painless ulcers with raised borders and a bed of granulation tissue. Cutaneousmucosal ATL, on the other hand, is characterized by aggressive lesions in the nasopharyngeal mucosa, and is usually caused by L. (Viannia) braziliensis. ${ }^{5}$

Although a diagnosis can sometimes be made based only on clinical-epidemiological criteria, laboratory tests are essential for the differential diagnosis between ATL and other infectious dermatoses, and to confirm the diagnosis before anti-leishmaniasis drugs (which have several potential side effects) are administered. ${ }^{4.6}$

A definitive diagnosis is only possible when the parasite species is identified through tissue slide examination, cultures in a specific medium, and hamster inoculation, as well as histopathological exams and polymerase chain reaction (PCR) analysis. Indirect immunological methods such as the Montenegro intradermal reaction and indirect immunofluorescence serology may also help with diagnostic confirmation. ${ }^{7}$

Histopathological studies have reported that, when cutaneous lesions first appear, the dermal infiltrate is mostly composed of macrophages with amastigote forms of the parasite, and relatively few lymphocytes and plasmocytes are present. As the lesion develops, there is an increase in the number of lymphocytes and plasmocytes in the upper dermis, which becomes spongiotic and is covered with hyperkeratotic epidermis, eventually progressing into an ulcer. During the ensuing months, the number of amastigotes and macrophages gradually reduces, leaving behind a granulomatous infiltrate composed of lymphocytes, epithelial cells and giant multinucleated cells. At this stage, it may be difficult or impossible to detect leishmaniasis by stain of smears or biopsies using hematoxylin-eosin (HE) or Giemsa. Lastly, if the patient's immune system is able to eliminate the parasite on its own, the ulcerated lesion subsides. However, when this does not occur, the patient may develop disseminated leishmaniasis. ${ }^{8,9}$

\section{MATERIALS AND METHODS}

A cross-sectional observational study was conducted using the records of 47 patients with clinical and histopathological diagnoses of ATL, seen at the outpatient clinic of a dermatology hospital in the state of São Paulo between 1999 and 2010.

Data regarding patient age, sex, place of birth, profession, site of cutaneous lesion, presence of mucosal lesions, clinical aspect of the lesion (ulcerated, papular, nodular or in plaques), duration of disease (months), indirect immunofluorescence serology (IFI) and Montenegro intradermal reaction (rM).

Patients were grouped according to their state of origin, and those who came from the state of São Paulo were separated into groups according to the Regional Health Department (RHD) which served their city.

The histopathological biopsy findings were semi-quantitatively classified using $H \& E$ staining. Samples received scores ranging from zero to three crosses, as displayed in table 1.

To avoid observation bias, all histological slides were assessed by the same pathologist, who was blind to patients' clinical, sorological, or epidemiological characteristics.

Data were analyzed using non-parametric tests. The Spearman correlation coefficient was used to investigate associations between variables, and results were considered significant at $p<0.05$.

\section{RESULTS}

A total of 47 patients with cutaneous and mucocutaneous leishmaniasis were studied. Fourteen of these individuals were female $(29.7 \%)$ while 33 were male $(70.2 \%)$. The mean age at diagnosis was 40.5 years (range: 7-79 years). The mean age of female participants was 34.5 years (range: 7-78 years), while the mean age of male patients was 43 years (range: 9-79 years).

The most commonly reported occupations were farmer (19 cases; $40.4 \%$ ), followed by student (9 cases; $19.1 \%)$, and most patients came from the area served by RHD VI (66\%). Mean time to diagnosis was 22.3 months.

The most common lesion sites were the limbs $(59.6 \%)$, followed by the face $(34 \%)$. The predominant clinical presentation was an isolated cutaneous lesion $(78.2 \%)$, which took the form of an ulcer $(53.2 \%)$ or plaque $(25.5 \%)$. Mucous involvement was present in $19.1 \%$ of patients.

The mean IFI was $1 / 130$ and mean rM diameter was $9.65 \mathrm{~mm}$.

The results of the parameters analyzed are displayed in table 2 .

Table 3 summarizes the histopathological characteristics of the slides reviewed.

There were no statistically significant gender differences in age, duration of disease, and immunological test results (rM and IFI).

The positive and negative correlations that reached statistical significance $(\mathrm{p}<0.05)$ are displayed in table 4 . 
TABLE 1: Semi-quantitative classification of histopathological findings in patients with Leishmaniasis

\begin{tabular}{|c|c|c|c|}
\hline & & Intensity & \\
\hline Zero & $(+)$ & $(++)$ & $(+++)$ \\
\hline \multicolumn{4}{|l|}{ EPITHELIAL REACTIVITY } \\
\hline Epithelial hyperplasia & Mild & Moderate & $\begin{array}{c}\text { Severe, } \\
\text { Pseudocarcinomatous }\end{array}$ \\
\hline Epithelial aggression & Mild & Moderate & Severe \\
\hline $\begin{array}{l}\text { NUMBER OF PARASITES } \\
\text { PER 1000X FIELD }\end{array}$ & $1-5$ & $6-10$ & $>11$ \\
\hline \multicolumn{4}{|l|}{ GRANULOMA CHARACTERISTICS } \\
\hline Differentiation & $\begin{array}{l}\text { Poorly differentiated } \\
\text { granuloma }\end{array}$ & $\begin{array}{l}\text { Moderately differentiated } \\
\text { granuloma }\end{array}$ & $\begin{array}{l}\text { Tuberculoid } \\
\text { granuloma }\end{array}$ \\
\hline Intensity of the inflammatory process & Upper dermis & Upper and mid dermis & Total dermis \\
\hline Degree of fibrosis & Mild & Moderate & Severe \\
\hline Necrosis & Mild & Moderate & Severe \\
\hline Hemorrhaging & Mild & Moderate & Severe \\
\hline Epithelioid cells & Poorly differentiated & Moderately differentiated & $\begin{array}{l}\text { Well- } \\
\text { differentiated }\end{array}$ \\
\hline Number of giant cells & Low & Moderate & High \\
\hline \multicolumn{4}{|l|}{ NUMBER OF CELLS IN } \\
\hline \multicolumn{4}{|l|}{ THE INFILTRATE } \\
\hline Plasmocytes & Low & Moderate & High \\
\hline Eosinophils & Low & Moderate & High \\
\hline Neutrophils & Low & Moderate & High \\
\hline $\begin{array}{l}\text { Lymphocytes } \\
(+) \text { intensity scores }\end{array}$ & Low & Moderate & High \\
\hline
\end{tabular}

$(+)$ intensity scores

TABLE 2: Results of the semi-quantitative analysis of histopathological findings in biopsied specimens

\begin{tabular}{lllll}
\hline & \multicolumn{3}{c}{ Intensity } & $\mathbf{( + + + )}$ \\
\cline { 2 - 4 } Histopathological characteristics & Zero & $\mathbf{( + )}$ & $\mathbf{( + + )}$ & $15(31.9 \%)$ \\
Epithelial hyperplasia & $11(23.4 \%)$ & $10(21.2 \%)$ & $11(23.4 \%)$ & $21(44.7 \%)$ \\
Epithelial aggression & $9(19.3 \%)$ & $5(10.6 \%)$ & $12(25.5 \%)$ & $6(12.7 \%)$ \\
Granuloma differentiation & $7(14.8 \%)$ & $20(42.5 \%)$ & $14(29.7 \%)$ & $39(83 \%)$ \\
Intensity of the inflammatory process & $0(0 \%)$ & $0(0 \%)$ & $8(17 \%)$ & $35(74.4 \%)$ \\
Degree of fibrosis & $0(0 \%)$ & $5(10.6 \%)$ & $7(14.8 \%)$ & $23(49 \%)$ \\
Necrosis & $4(8.5 \%)$ & $8(17 \%)$ & $12(25.5 \%)$ & $4(8.5 \%)$ \\
Epithelioid cells & $5(10.6 \%)$ & $21(44.6 \%)$ & $17(36.1 \%)$ & $2(4.2 \%)$ \\
Giant cells & $10(21.2 \%)$ & $25(53.2 \%)$ & $10(21.2 \%)$ & $20(42.5 \%)$ \\
Plasmocytes & $0(0 \%)$ & $7(14.8 \%)$ & $20(42.5 \%)$ & $1(2.1 \%)$ \\
Eosinophils & $38(80.8 \%)$ & $5(10.6 \%)$ & $3(6.3 \%)$ & $6(12.7 \%)$ \\
Neutrophils & $5(10.6 \%)$ & $13(27.6 \%)$ & $23(49 \%)$ & $21(44.7 \%)$ \\
Lymphocytes & $0(0 \%)$ & $0(0 \%)$ & $26(55.3 \%)$ & $13(27.7 \%)$ \\
Edema & $9(19.3 \%)$ & $12(25.5 \%)$ & $13(27.7 \%)$ & $13(27.7 \%)$ \\
Hemorrhaging & $7(14.8 \%)$ & $5(10.6 \%)$ & $12(25.5 \%)$ & $8(17 \%)$ \\
Number of parasites per 1000X field & $9(19.3 \%)$ & $15(31.9 \%)$ & $15(31.9 \%)$ & \\
\hline
\end{tabular}

$(+)$ intensity scores 
TABLE 3: Quantitative and semi-quantitative results of parameters analyzed in patients with american tegmentary leishmaniasis

\begin{tabular}{ll}
\hline Characteristics & MEAN \pm SD* \\
\hline & \\
Quantitative variables** & \\
Age (years) & $40.6 \pm 20.8$ \\
Time (months) & $22.3 \pm 70.8$ \\
Serology( Indirect Immunofluorescence) $10^{-1}$ & $130 \pm 243$ \\
Size of montenegrio reaction (milimeters) & $9.65 \pm 3.94$ \\
& \\
Intensity of histopathological findings (crosses) \\
Epithelial hyperplasia & $1.59 \pm 1.15$ \\
Granuloma differentiation & $1.38 \pm 0.87$ \\
Plasmocytes & $2.25 \pm 0.73$ \\
Epithelioid cells & $1.40 \pm 0.77$ \\
Giant cells & $1.06 \pm 0.73$ \\
Eosinophils & $0.29 \pm 0.69$ \\
Lymphocytes & $2.44 \pm 0.50$ \\
Neutrophils & $1.51 \pm 0.83$ \\
Edema & $1.63 \pm 1.05$ \\
Intensity of the inflammatory process & $2.79 \pm 0.41$ \\
Hemorrhaging & $2.06 \pm 1.07$ \\
Fibrosis & $2.63 \pm 0.67$ \\
Epithelial aggression & $1.46 \pm 0.97$ \\
Necrosis & $1.98 \pm 1.15$ \\
& $2.12 \pm 0.99$ \\
& \\
& \\
&
\end{tabular}

* SD: Standard deviation.

**Assessed using the Mann-Whitney test

\section{DISCUSSION}

ATL is usually diagnosed in patients who live in endemic regions and present with asymptomatic lesions, most commonly in the form of ulcers with raised borders. ${ }^{5,6}$ These observations were confirmed by the present investigation, which also found that isolated ulcers were the most common manifestation of ATL. Most lesions were located on the face and limbs, areas which are exposed and easily accessible by vector insects.

Patients had a mean age of 40.5 years, and most were found to be male $(70.8 \%)$, with the most common occupations being farmer $(40.4 \%)$, student $(19.1 \%)$ and homemaker $(10.6 \%)$. The positive correlation between patient age and disease duration, as well as the long time taken to seek medical help, could be explained by the asymptomatic nature of the lesions, which could have led them to be ignored by individuals with rural occupations or low sociocultural levels. Studies conducted in southeast and southern Brazil have reported similar epidemiological findings. ${ }^{10,11}$

The epidemiology of leishmaniasis in Brazil has changed over recent years. Initially, ATL was considered a wild animal zoonosis, which was accidentally transmitted to humans when they came into contact with forests for exploration, logging, road building or mining purposes. The condition was, therefore, a professional disease, which only affected male individuals. However, more recently, the intense environmental changes associated with deforestation and agricultural development have also made farmers vulnerable to the disease. ${ }^{10}$ In Brazil, although there appeared to be a decrease in the types of leishmaniasis reported in the 1950s, the number of cases has been progressively increasing over the past 20 years. Currently, the Lutzomia intermedia parasite appears to be responsible for most cases of ATL in rural areas. Most patients in the state of São Paulo, however, are infected by L. brasiliensis, which has been found to be more commonly carried by domestic animals, such as dogs, than by wild ones. ${ }^{12,13}$ In areas where the pathogen is present, although some cases are related to professional activities, there have also been reports of transmission among women and children. ${ }^{14}$

The Montenegro reaction is an indirect method to detect previous exposure to leishmaniasis, and is often used in epidemiological studies to assess the prevalence of the disease..$^{15}$ It consists of a late hypersensitivity reaction (type IV), which simulates the granulomatous reaction that generally occurs in later phases of leishmaniasis. This explains the positive association between the size of the Montenegro test and the duration of the disease. Positive reactions may be detected within three months of the infection, and occur in 82 to $100 \%$ of patients with cutaneous leishmaniasis. ${ }^{16,17,18,19}$ However, the test has limited diagnostic utility in endemic areas, as positive results may be obtained in patients without active lesions or with cicatricial lesions, suggesting the presence of subclinical infection or of other coexisting conditions. ${ }^{7,17}$ In the present sample, early exposure to the parasite induced a positive immunological response in most individuals. In many cases, this is associated with spontaneous healing, which would explain the positive association between patient age, Montenegro test positivity, the degree of granulomatous transformation, and the number of epithelial cells, as well as the negative relationship between age and serology, since antibody titers were inversely proportional to effective cell response.

In all forms of the disease, the amastigote proliferates in the histiocytes of the host, whose immune response is inversely related to the quantity of parasites present (Jadassohn-Lewandowski Law) ${ }^{20}$ The presence of large numbers of amastigotes induces an 
TABLE 4: Statistically significant correlations between clinical, laboratory and histopathological findigns (Spearman's test, p<0.05)

\begin{tabular}{|c|c|}
\hline Positive correlations & P value* \\
\hline Age and time & 0.022 \\
\hline Age and Montenegro reaction & 0.031 \\
\hline Age and degree of granulomatous transformation & 0.042 \\
\hline Age and number of epithelial cells & 0.049 \\
\hline Time and Montenegro reaction & 0.010 \\
\hline Time and number of lymphocytes & 0.003 \\
\hline Montenegro reaction and epithelial aggression & 0.024 \\
\hline Epithelial hyperplasia and edema & 0.003 \\
\hline Epithelial hyperplasia and hemorrhaging & 0.001 \\
\hline Epithelial hyperplasia and epithelial aggression & 0.000 \\
\hline Granulomatous transformation and number of epithelioid cells & 0.000 \\
\hline Granulomatous transformation and number of giant cells & 0.016 \\
\hline Number of plasmocytes and number of parasites & 0.004 \\
\hline Number of epitheilioid cells and number of giant cells & 0.008 \\
\hline Hemorrhaging and epidermal necrosis & 0.000 \\
\hline Negative correlations & P value* \\
\hline Age and serology & 0.036 \\
\hline Time and number of parasites & 0.024 \\
\hline Montenegro reaction and degree of fibrosis & 0.032 \\
\hline Epithelial hyperplasia and degree of granulomatous transformation & 0.048 \\
\hline Number of epithelioid cells and epidermal aggression & 0.024 \\
\hline Number of giant cells and number of parasites & 0.007 \\
\hline
\end{tabular}

anergic response, characterized by many multinucleated histiocytes containing "Montenegro gaps," or vacuoles filled with parasites, and almost no other inflammatory cells. A moderate number of parasites is generally associated with necrosis, an important method to eliminate infection, since some infections are eliminated by an effective granulomatous response, while others are associated with focal necrosis and ulceration. ${ }^{21,22}$ In the present study, the degree of hemorrhage and necrosis were assessed, but were not found to be related to any other variables. The events following necrosis depend largely on the degree of granulomatous response. ${ }^{21,22}$ The number of parasites was found to be inversely correlated with the number of giant cells and with the time to diagnosis, demonstrating the importance and effectiveness of the granulomatous transformation in eliminating leishmaniasis.

The presence of giant and epithelioid cells suggest the end of the process of intracellular parasite destruction. In parallel, the continued presence of the antigen and the development of the hypersensitive granulomatous response, as well as the consequent release of interferon by $\mathrm{T}$ lymphocytes, may induce epithelial hyperplasia in the overlying epidermis, leading, at times, to pseudocarcinoma. ${ }^{23,24}$ The occurrence of secondary infection in ulcerated lesions would also explain the small to moderate number of neutrophils, and the increase in the number of lymphocytes and plasmocytes around the granuloma, all of which could have led to the positive association between time to diagnosis and the intensity of lymphocytic infiltrate. ${ }^{25}$

The Montenegro reaction assesses the organism's ability to generate a granulomatous response against the parasite. This response could occur through the production of torpid (non-reactive) granuloma, or through intense hypersensitivity reactions. ${ }^{20}$ In the present study, positive associations were identified between epithelial hyperplasia and edema, hemorrhage, and epithelial aggression, as well as between the size of the Montenegro reaction and epithelial aggression, indicating that the cell-mediated hypersensitivity reactions had to be increased so as to successfully eliminate the parasite. This process explains the presence of a moderate to high number of $\mathrm{T}$ and $\mathrm{B}$ lymphocytes in the infiltrate, of moderate to severe fibrosis, and of moderate epithelial aggression, 
hemorrhage and necrosis. Interestingly, edema was not as significant a finding, as it was less severe when compared to the other components of the hypersensitivity reaction.

It is important to note that the exacerbation of the reaction is not essential for cure. A granulomatous process that did not induce tissue damage would be more beneficial overall, and even more effective in eliminating the parasite. This relative absence of exacerbated cell-mediated immune reactions, causing less epithelial and dermal damage, would also explain the apparently paradoxical negative association between epithelial hyperplasia and granulomatous transformation, epidermal aggression, and number of epithelioid cells, and between the size of the Montenegro reaction and fibrosis. Therefore, a quick and effective immune response, involving a high rate of macrophage transformation and no long-term hypersensitivity, would result in less fibrosis and epithelial hyperplasia.

A comparison between the immune responses to ATL and to other conditions caused by intracellular parasitism, such as leprosy, shows that an effective granulomatous response, that is, one which is able to completely eliminate the parasite (tuberculoid leprosy - TT), does not induce epithelial hyperplasia: this only occurs when hypersensitivity is present, such as in type 1 and 2 reactions in dimorphic patients who have partial immunity. ${ }^{26,27}$

Positive associations were also found between the number of giant and epithelioid cells, as well as between these two variables and granulomatous transformation. Although epithelioid cells have a lower phagocytic capacity and are stationary, they have a much larger arsenal of substances that are toxic to parasites, and produce a significant number of cytokines. ${ }^{26.28}$

A positive correlation was found between the numbers of plasmocytes and parasites. According to the literature, the most common immune response to ATL is mixed Th1/Th2. T CD4+ lymphocytes are divided into two populations according to the pattern of cytokines they secrete: while Th1 cells characteristical- ly produce INF $\gamma$ and IL-2, Th2 cells secrete IL-4, IL-5 and IL-10. ${ }^{29}$ Th1 lymphocytes activate macrophages through the release of INF $\gamma$, which acts synergically with TNFalpha to destroy the microorganism inside the phagolysosome. ${ }^{30}$ The Th2 response activates B lymphocytes and transforms them into plasmocytes, which secrete the immunoglobulins necessary for opsonization and the phagocytic response. This process eventually leads to extracellular antibody-dependent cytotoxicity. The fact that this process only rarely occurs in leishmaniasis explains the low number of eosinophils present in biopsy samples. However, the increased number of plasmocytes indicates a prevalence of humoral immune responses, which suppress cell immunity and are ineffective in intracellular parasitic infections. ${ }^{29}$

The mean length of time to diagnosis, which was of almost 2 years in the present sample, would also explain the relatively low number of parasites present, which was directly proportional to the number of epithelioid and giant cells, and to granulomatous activity.

\section{CONCLUSION}

Although study participants came mostly from an endemic area, mucosal compromise was rare, possibly due to a combination of healthy immune systems, short follow-up duration, or infection by less pathogenic Leishmania species.

However, the fact that students and housewives were affected suggests that both vector and parasite are present in the studied area.

The long disease duration could be related to the fact that lesions were relatively asymptomatic, and therefore, probably ignored by patients with a low cultural level. The high frequency of histopathological signs of hypersensitivity corroborated this hypothesis, and suggested that individuals may have simply waited for the lesion to spontaneously resolve. When this failed to occur, hypersensitivity responses were elicited, and eventually led to tissue damage. 


\section{REFERENCES}

1. Goto H, Lindoso JA. Current diagnosis and treatment of cutaneous and mucocutaneous leishmaniasis. Expert Rev Anti Infect Ther. 2010;8:419-33.

2. Viana AG, Fraga CA, Batista Domingos PL, Bonan PR.. Evaluation of myofibroblasts and its association with TGF- $\beta$ and IFN- $\gamma$ in lesions of patients with american tegumentary leishmaniasis. An Bras Dermatol. 2012;87:545-9.

3. Murback ND, Hans Filho G, Nascimento RA, Nakazato KR, Dorval ME. American cutaneous leishmaniasis: clinical, epidemiological and laboratory studies conducted at a university teaching hospital in Campo Grande, Mato Grosso do Sul, Brazil. An Bras Dermatol. 2011;86:55-63.

4. Hepburn NC. Cutaneous leishmaniasis: an overview. J Postgrad Med. 2003;49:504.

5. Gontijo B, Carvalho MLR. Leishmaniose tegumentar americana. Rev Soc Bras Med Trop. 2003;36:71-80.

6. Schubach Ade 0, Marzochi KB, Moreira JS, Schubach TM, Araújo ML, Vale AC, et al . Retrospective study of 151 patients with cutaneous leishmaniasis treated with meglumine antimoniate. Rev Soc Bras Med Trop. 2005;38:213-7.

7. Lima Junior MS, Andreotti R, Dorval ME, Oshiro ET, Oliveira AG, Matos Mde F. Identification of Leishmania species isolated in human cases in Mato Grosso do Sul by means of polymerase chain reaction. Rev Soc Bras Med Trop. 2009;42:303-8.

8. Botelho AC, Tafuri WL, Genaro 0, Mayrink W. Histopathology of human American cutaneous leishmaniasis before and after treatment. Rev Soc Bras Med Trop. 1998;31:11-8

9. Silveira FT, Lainson R, Corbett CE. Clinical and imunopathological spectrum of American cutaneous leishmaniasis with special reference to the disease in Amazonian Brazil- A review. Mem Inst Oswaldo Cruz. 2004;99:239-51.

10. de Castro EA, Soccol VT, Membrive N, Luz E. Epidemiological and clinical study of 332 cases of cutaneous leishmaniasis in the north of Parana State from 1993 to 1998. Rev Soc Bras Med Trop. 2002;35:445-52.

11. Neves VLFC, Gomes AC, Antunes JPF. Correlation of the presence of phlebotominae species (Diptera: Psichodidae) with records of American tegumentary leishmaniasis cases in the State of São Paulo, Brazil. Rev Soc Bras Med Trop. 2002;35:299-306.

12. Silva LMR, Cunha PR. Urbanization of American Cutaneous Leishmaniasis in Campinas - Sao Paulo (SP) and region: problems and challenges. An Bras Dermatol. 2007;82:515-9.

13. Menezes JA, Reis VLL, Vasconcelos JA. Pequeno surto de leishmaniose tegumentar americana em Macuco (Cordeiro- RJ). Rev Soc Bras Med Trop 1974;8:133-51.

14. Brasil. Ministério da Saúde. Manual de Vigilância da Leishmaniose Tegumentar Americana. 2. ed. atual. Brasília: Ministério da Sáude; 2007. 180 p. - (Série A. Normas e Manuais Técnicos)

15. Nogueira MF, Sotto MN, Cucé LC. American Tegumentary Leishmaniasis: Langerhans Cells in Montenegro skin test. Rev Inst Med Trop Sao Paulo. 2008;50:283-6.

16. Castilho TM, Camargo LM, McMahon-Pratt D, Shaw JJ, Floeter-Winter LM. A real time polymerase chain reaction assay for the identification and qualification of American Leishmania species on the basis of glucose-6-phosphate sehydrogenase. Am J Trop Med Hyg. 2008;78:122-32.

17. Sassi A, Louzir H, Ben Salah A, Mokni M, Ben Osman A, Dellagi K. Leishmanin skin test lymphoproliferative responses and cytokine production after symptomatic or asymptomatic Leishmania major infection in Tunisia. Clin Exp Immunol. 1999;116:127-32.
18. Reed SG. Diagnosis of leishmaniasis. Clin Dermatol. 1996;24:471-8.

19. Luz ZM, Silva AR, Silva Fde 0, Caligiorne RB, Oliveira E, Rabello A. Lesion aspirate culture for the diagnosis and isolation of Leishmania. Mem Inst Oswaldo Cruz. 2009;104:62-6.

20. 20. Elder DE, Elenitsas R, Johnson Jr B, Murphy GF, editors. Lever's histopathology of the skin. 9th ed. Philadelphia: Lippincott Williams and Wilkins; 2005.

21. Ridley DS, Ridley MJ. The evolution of the lesion in cutaneous leishmaniasis. J Pathol. 1983;141:83-96.

22. Ridley DS, De Magalhaes AV, Marsden PD. Histological analysis and the pathogenesis of cutaneous leishmaniasis. J Pathol. 1989;159:293-9.

23. Kaplan G, Witmer MD, Nath I, Steinman RM, Laal S, Prasad HK, et al. Influence of delayed immune reactions on human epidermal keratinocytes. Proc Natl Acad Sci U S A. 1986;83:3469-73.

24. Peltier E, Wolkenstein P, Deniau M, Zafrani ES, Wechsler J. Caseous necrosis in cutaneous leishmaniasis. J Clin Pathol. 1996;49:517-9.

25. Grayson W, Calonji E, Mckee PH. Infectious diseases of the skin. In: Mckee PH, Calorize E, Gahter SR, editors. Pathology of the skin. 3rd ed. London: Elsevier mosby; 2005. p. 957-8.

26. Ridley DS. Histological classification and the immunological spectrum of leprosy. Bull World Health Organ. 1974;51:451-65.

27. Montenegro MR, Franco M. Patologia Processos Gerais. 4. ed. São Paulo: Atheneu, 1999.

28. D'Oliveira A Jr, Machado P, Bacellar 0, Cheng LH, Almeida RP, Carvalho EM. Evaluation of IFN-gamma and TNF-alpha as immunological markers of clinical outcome in cutaneous leishmaniasis. Rev Soc Bras Med Trop. 2002;35:7-10.

29. Abbas AK, Litchtman AH, Pillai S. Imunologia celular e Molecular. 6. ed. São Paulo: Elsevier; 2008.

30. Roitt IM, Delves PJ. Fundamentos de Imunologia. 10. ed. Guanabara Koogan, 2004.

How to cite this article: Martins ALGP, Barreto JA, Lauris JRP, Martins ACGP American tegumentary leishmaniasis: correlation among immunological, histopathological and clinical data. An Bras Dermatol. 2014;89(1):52-8. 